\title{
Achieving sustainability and environmental enhancements through a "collaboration toolkit" to deliver new sustainability strategies for The Emirate of Ajman - UAE
}

\author{
Jason Challender \\ Director of Estates and Facilities, Bolton, England
}

Received: 26 February 2021 / Received in final form: 6 April 2021 / Accepted: 6 April 2021

\begin{abstract}
Governments are faced with ever challenging dilemmas to find practical sustainable solutions and proposals for some scientific and problems around adopting clean sustainable energy whilst reducing waste. This is certainly an issue for Ajman which has been heavily dependent on fossil fuels for energy and had a detrimental and adverse effect on its environmental sustainability credentials in the past. This paper focuses on the use of a "collaboration toolkit" has been developed by the author and which is currently being piloted in the UK on a live project. The sole purpose of the toolkit is to deliver improved environmental sustainability solutions on construction and engineering projects. The toolkit will provide a holistic and joined up approach across the supply chain to meet the demands of the carbon neutral agenda. This will entail reducing embodied carbon in buildings, collaboration with energy partners to assess ways and means of reducing gas, electricity and water consumption and reviewing appropriate renewable technologies. It is hoped that the toolkit can prove beneficial for Ajman in overseeing a new environmental sustainability strategy for its construction and engineering projects and therein contributing to overall social, environmental and economic impacts.
\end{abstract}

\section{Introduction}

\subsection{The need for Ajman to be leading the way on environmental sustainability}

For many years now there has been a global call for nations to come together, to address environmental issues, reduce the damage to the planet and mitigate against climate change. Ajman should recognise that the global crisis around carbon emissions and global warming around the world and accordingly respond positively to an agenda of environmental sustainability improvements. The collaboration toolkit on construction and engineering projects can contribute to achieving positive outcomes with its objectives firmly centred around improving environmental sustainability performance through supply chain interface. If utilised fully it can fully embrace management of environmental sustainability on all projects and mitigate climate change.

\subsection{Introduction to the collaboration toolkit as a means to improve environmental sustainability}

The collaboration toolkit was developed by the author as part of a PhD completed in 2016 and is regarded as an

\footnotetext{
* e-mail: jasonchallender@hotmail.co.uk
}

enabler to encourage collaboration and partnership working when addressing environmental projects and initiatives. For the last 3 years it has been introduced as part of ongoing major construction projects in the UK as part of a wider development masterplan. Accordingly, this research covers the environmental sustainability measures and benefits that the toolkit has brought about in this regard. It is hoped that such benefits could replicated be replicated on future project in Ajman, by using similar partnering philosophies and the use of the collaboration toolkit. The collaboration toolkit is intended on a projectby-project basis to present itself as a useful practical guide to encourage environmental sustainability to be embedded in all aspects which will enable beneficial impacts to be made for society and environment.

\section{Literature review}

\subsection{Introduction to the discussion on trust, partnership which the collaboration toolkit is predicated upon}

According to Patel et al. [1], working within partnerships and encouraging collaboration between organisations has been widely heralded as a successful means of procuring positive relationships and achieving successful project 
outcomes. Further evidence of the benefits of collaborative working has been articulated by CIC [2], who regard such partnering practices as producing win-win scenarios for construction and engineering projects.

In the past there has been much criticism of traditional construction procurement practices which have resulted in less than satisfactory project outcomes [3-5]. Such criticism has revolved around procuring construction and engineering projects on a lowest tender price basis. Such an approach has normally reflected a single stage tender approach with very little or no supply chain interface in the design stages. Many have argued for the supply chain, including main contractors and specialist sub-contractors, to become engagedat the earliest designstages of projects to introduce buildability and solve potential problems which may otherwise emerge in the construction phase. One such advocate was Vaaland [6], who argued that collaborative and partnership working was a prerequisite for successful projects, where designers and contractors come together to forge good working relationship predicated on trust and respect for one another.

Notwithstanding this premise, according to Chow et al. [7] and Kumaraswamy et al. [8,9], there is still little evidence that such practices are being widely practiced; the construction industry is still being regarded as having a poor and unsatisfactory level of satisfaction from clients and the general public as a result of inconsistent project outcomes. According to Ross [10], time and cost predictability remain a real issue for the industry which has had an adverse effect on trust and confidence to deliver construction projects to clients' satisfaction.

\subsection{Trust as a collaborative necessity}

The important for trusting relationships in business dealings cannot be underestimated (Ceric, 2014) and in the past according to Dainty et al. [11], this is a prerequisite for collaborative working and partnering. According to Langfield-Smith [12] and Silva et al. [13] collaborative working practices are regardedas the "cement" which bonds relationships together. Furthermore, according to [14], such practices will encourage parties to collaborate further in the future based on established trusting relationships.

\subsection{The benefits of instilling collaborative and trusting relationships}

In the past the construction and engineering industries have been associated with an environment where win-fail outcomes are experienced rather than win-win. This normally is associated with adversarial relationships between design team consultants and contractors who regard themselves as being at polar opposite ends of the overall project team. In certain instances, according to Silva et al. [13], this has created the scope for optimism to thrive. In this context the presence of trust has overcome such adversities and encouraged projects teams to collaborate on designs and construction issues which has had many beneficial results. According to [15] and [16], such benefits have included reducing the number of conflicts and disputes on building contracts and the propensity for parties to work more transparently in their dealing with other organisations. This is an important consideration articulated by $[17,18]$, that given that it is not feasible to include every contract clause or provision for all possible occurrences that may emerge. For this reason, trust becomes a vehicle which reduces the risk that relationships could be adversely impacted, especially when unexpected construction events occur on projects.

\section{Action research around the collaboration toolkit}

\subsection{Developing the collaboration toolkit for a means to improve project outcomes}

The collaboration toolkit was developed from a perspective that considered what initiatives and measures can be adopted by project teams to add value to the way construction and engineering developments are managed. Such measures were predicated on a literature review which identified key areas where significant improvements to management practices, especially around partnership working, could be embedded into projects. In this regard a list of trust-building mechanisms was devised for organisations to consider when embarking on projects. The list was very much considered to be generic, but the specific measures tailored around the nature of the individual projects. Table 1 contains the list of measures, which have been described as trust-building mechanisms, incorporated into a collaboration toolkit template. These measures include specialist workshops, incentivisation schemes, open book systems for financial management and communications strategies.

\subsection{The ways and means of embedding the collaboration toolkit into project management practices at different design stages}

As a means to understand how the collaboration toolkit can align with project management processes in construction and engineering the flowchart in Figure 1 has been prepared to assist practitioners. The flowchart covers four main stages of projects from cradle to grave and is intended as a collaboration framework. These stages include:

- Initiation and planning

- Design and procurement

- Construction and delivery

- Close and post project review.

The flowchart maps out the various stages and decisionmaking points within these stages. For clarity the flowchart has been developed in sync with the RIBA Plan of Work. It is intended to provide a comprehensible and easy to follow practical guide for practitioners to enable them to introduce collaborative strategies into their projects and 


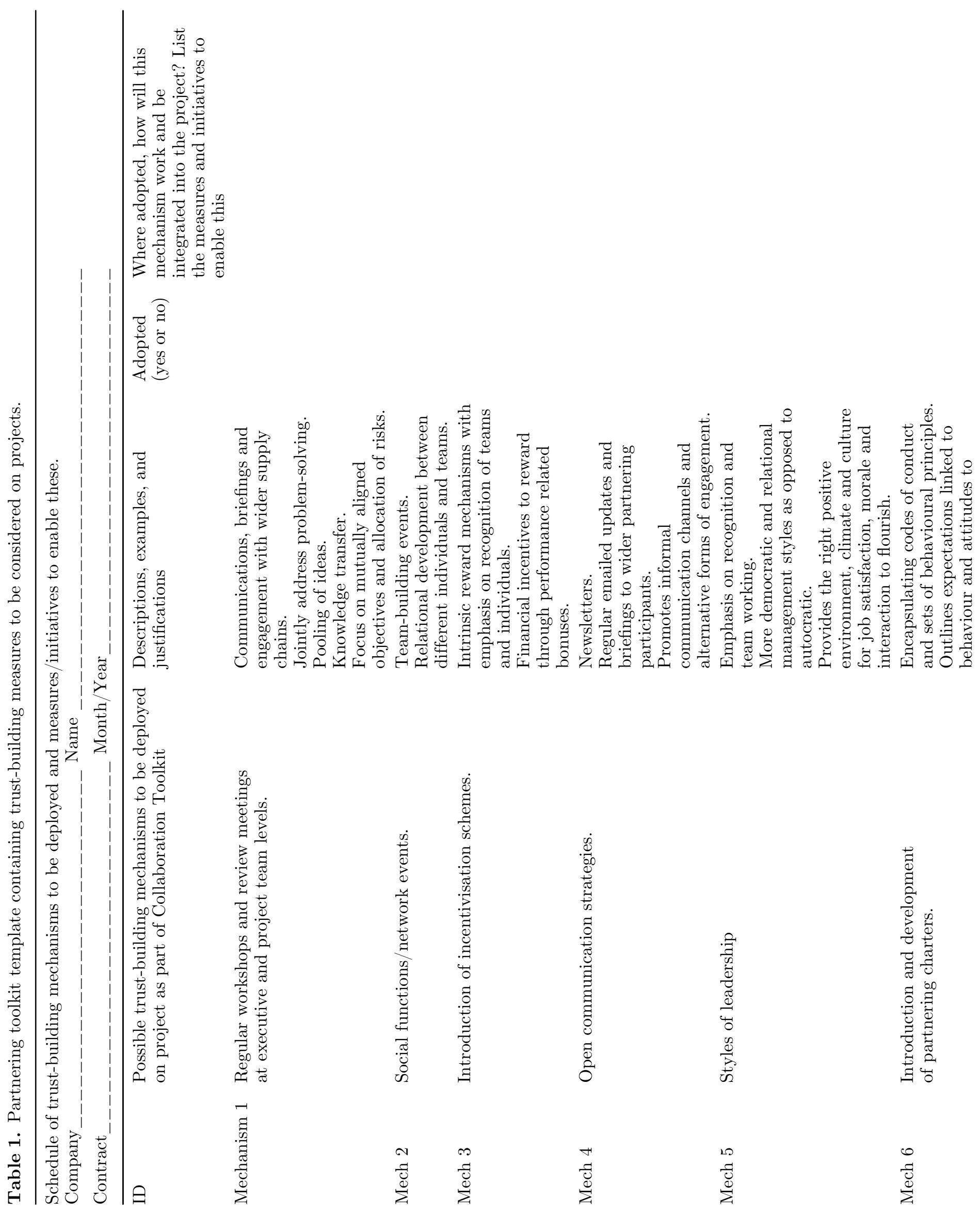




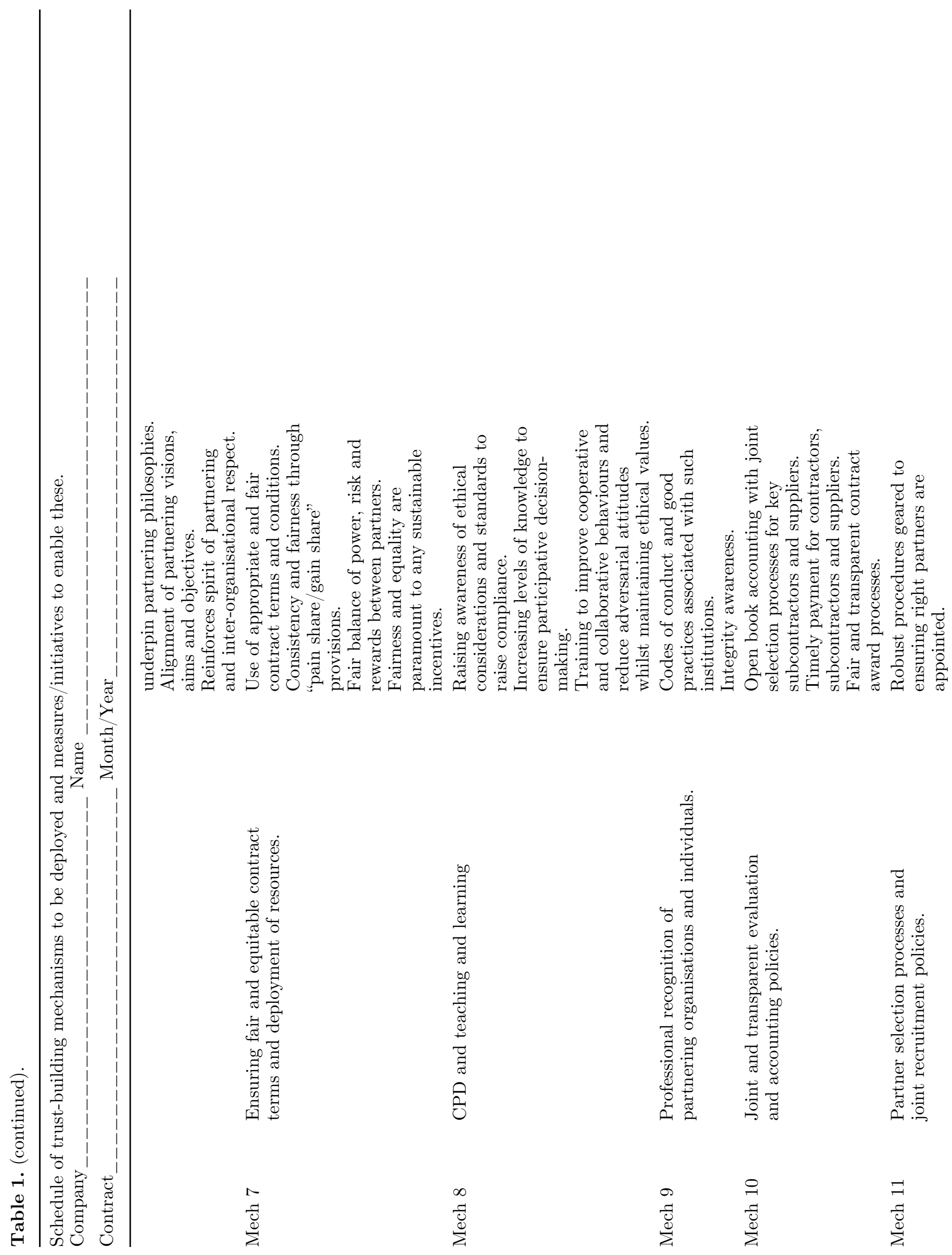




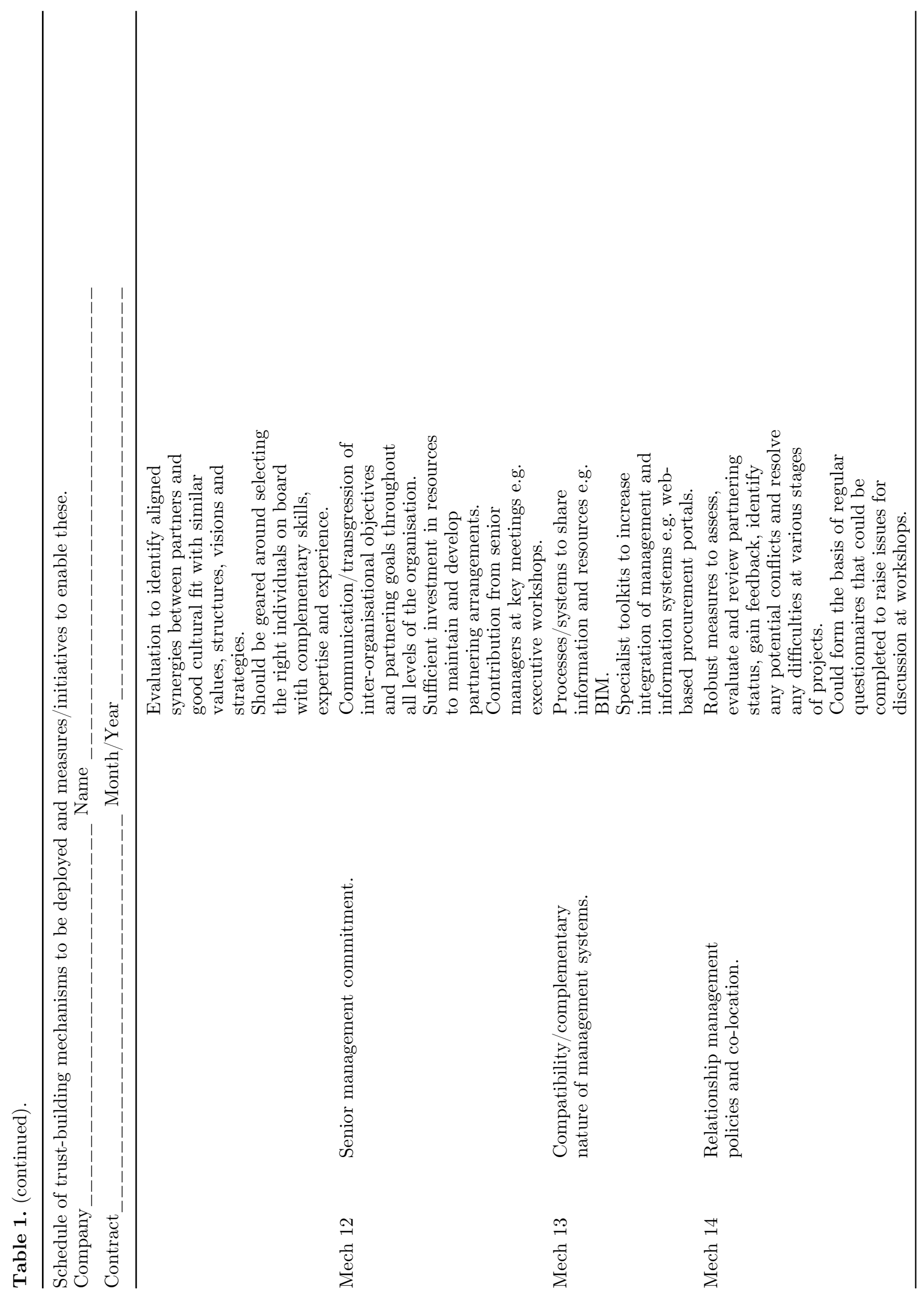




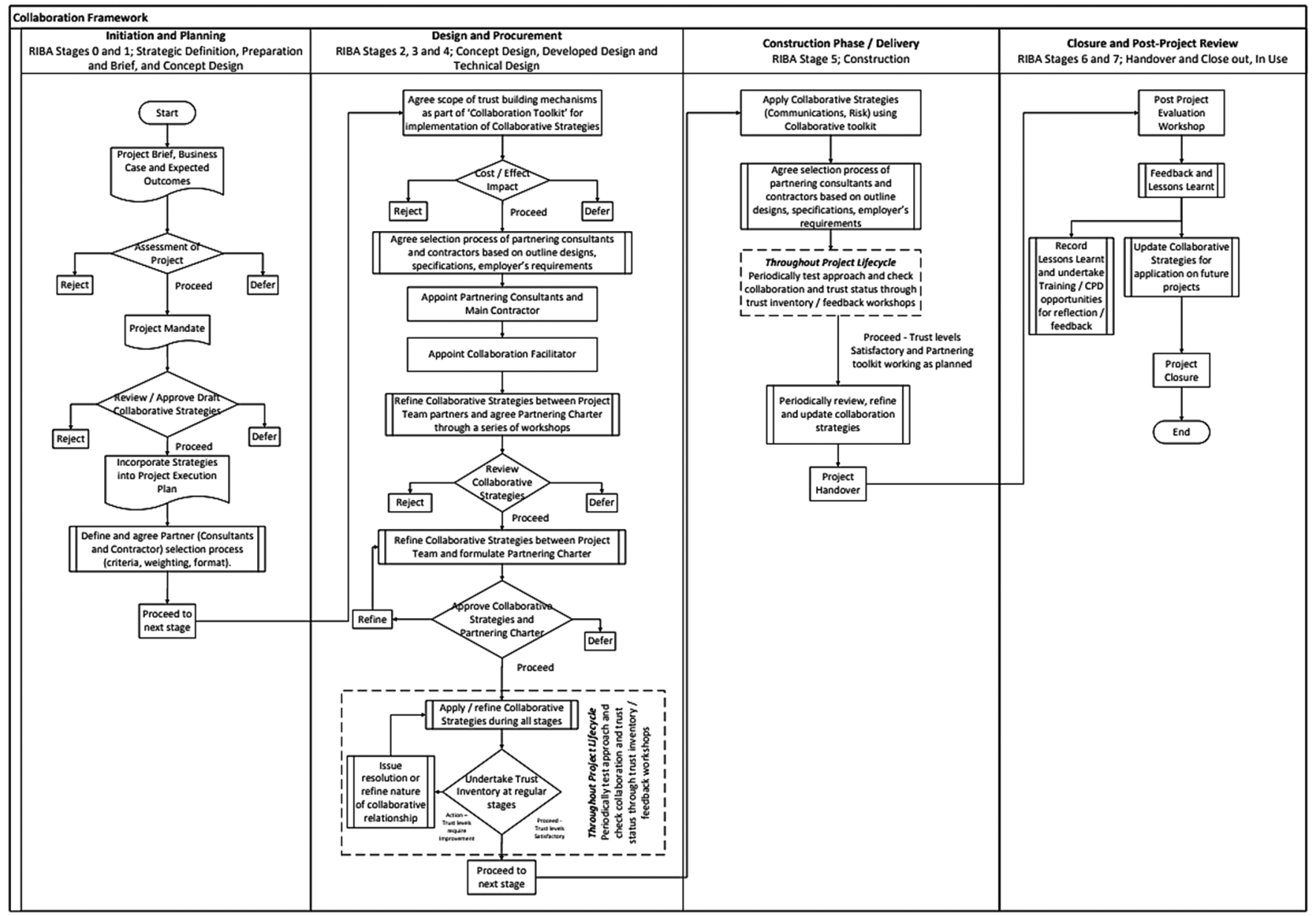

Fig. 1. Illustrates the flowchart of different stages where the collaboration toolkit can be utilised.

therein benefit from the supply chain contributing to issues such as buildability, innovation, prefabrication in their environmental sustainability projects.

\subsection{The role of a collaboration champion}

Whilst the collaboration toolkit is predicated on existing partnering philosophies, principles and procurement methodologies, it was felt that a new role within the project team was required to oversee the process of partnership working throughout all the stages. This role has been designated the position of "Collaboration Champion" and ensures that the right and appropriate level of resources are applied to making the collaboration process work in practice. The role would also serve the ensure that the Collaboration Champion is jointly appointed by the project team and therein is not affiliated with one party, for example clients, and therein avoid compromising the interests of one party. This is a very important component of making the collaboration strategies work best where its role is needs to work for the whole team. Having this separate role will also ensure that other considerations such as design, costs, programme are not primary concerns for the Collaboration Champion. In this way they can focus on the mechanisms and process of partnership working without being distracted on day-to-day project management issues that arise.

\subsection{Continuous reflection of the toolkit, lessons learnt, and implementation of improvements where required}

The collaboration framework and the toolkit are not intended to be rigid and restrictive when applied to construction and engineering projects. It is important for them to be sufficiently flexible enough to enable adaptationas required by project teams. There will be many periods of reflection on the use of the toolkit where lessons learnt from practice will necessitate it being improved or used differently on future projects. This follows the principles of Kolb's Learning Model, as advocated by [19], wherein experience from doing and the lessons learnt from this can influence the way things are done next time around.

\section{Findings from case studies}

\subsection{Measuring and evaluating the effectiveness of the toolkit for construction and engineering projects}

As part of the qualitative research from case studies where the collaboration toolkit is being used on live projects, through interviews with practitioners the following trustbuilding mechanisms were considered to be particularly useful in bringing about beneficial outcomes: 
- Arrange regular workshop with the project team to discuss and agree solutions to problems and challenges

- Devise innovative solution to align the ambitions and aspirations of the contracting organisations

- Adopt initiatives relating to sharing the pain and rewards from adopted and agreed measures.

- Adopt anopen approach to financial accounting and valuation matters

- Orchestrate excellent comms policies linked to engaging all interested parties in the progress of the project

- Adopt styles of management that are diplomatic and empathetic

- Ensure that fairness, equality and reward/risk balances between parties is maintained

- Commit sufficient resources to projects

- Involve senior leadership in strategic development and making key decision

- Create selection processes for consultants and subcontractors which aligned between the partners

- Implement efficient processes and system to share information and documentation

- Introduce democratic and fair processes for issue escalation before problems become disputes.

\subsection{Practical use of the collaboration toolkit to target and deliver environmental sustainability objectives}

The collaboration toolkit provides the practical guidance and the platform for systematic partnering at all design and construction stages with the supply chain. This is intended to provide the conduit for improving outcomes on projects as part of strategies designed around environmental sustainability. Notwithstanding this premise the following considerations need to be integrated into environmental sustainability strategies and policies.

\subsubsection{The need for an effective environmental management} system

As "part and parcel" of the sustainable procurement of construction and engineering projects an Environmental Management System should be put in place as a way for organisations to demonstrate that they have addressed and minimised the environmental impacts of development. In this way it can oversee and manage legal compliance of development whilst striving for continuously improvement on environmental sustainability performance. Furthermore Figure 2 shows the environmental measures which should be incorporated into the Environmental Management System project management of construction and engineering development throughout the whole life cycle.

In addition to the above measures, having energy, water and carbonmanagement plans in place can greatly improve the success of environmental sustainability projects. The collaboration toolkit can be tailored to ensure that these plans area developed by the projects team, assisted by the supply chain and then become embedded into construction and engineering programmes.

\subsubsection{Waste reduction}

On all projects through the collaboration toolkit there should be integrated measures to ensure that waste from construction and engineering activities is minimalised. Every effort should be made to recycle waste materials and thus reduce the overall amount of arisings disposed off-site. This will serve to reduce the embedded carbon of the build process thus lowering the carbon footprint. Furthermore, measures to improve the green credentials and status of projects will have many advantages for those organisations involved in them, and these revolve around corporate social responsibility, community relations and reputation.

\subsubsection{Sustainable and ethical procurement}

In a construction and engineering context sustainable procurement philosophies should be deployed as part of the collaboration toolkit when appointing consultants, main contractors, sub-contractors, suppliers and other specialists. In the UK there are various purchasing consortiums, who ensure that "checks and balances" are conducted on those organisations that are included as part of their framework. Such checks will ascertain the ethical and sustainability credentials of organisations and ensure that only those firms which meet a required minimum standard are included on the framework. In this way, employers can have the comfort factor that companies who are commissioned on projects have already been through a rigorous vetting process to assess their environmental sustainability credentials. Furthermore, organisations should ensure that all tender evaluations required when appointing the supply chain include sustainability weighting as a key quality factor alongside other criteria such as price. Developing and applying ethical and sustainable procurement policies in this way will ensure social and environmental impacts of those employed on construction and engineering projects are appropriately considered.

\subsubsection{Sustainable construction and engineering designs and technologies}

The collaboration toolkit should be able to assist project teams in making collaborative decisions with their supply chains on the use of environmentally sustainable building technologies in the construction process. This could entail careful and protracted early discussions on the use of renewable technologies. Reducing embedded carbon in construction and engineering projects is a topical issue in the UK and cross discipline dialogue with the supply chain has encouraged more sustainable materials and construction processes to be implemented within projects. Accordingly, sustainability as the core principle of the any project and should embed a high standard of adherence to best practice philosophies.

\subsubsection{Community engagement}

Communication and engagement, encouraged and facilitated through the collaboration toolkit at all construction and engineering stages, are regarded as good practice on 
Gathering data e.g., energy use, waste, water, raw materials

An initial assessment of how the organisation's activities, products and services might affect the environment

Identifying risks and opportunities associated with environmental issues

Making sure the organisation's activities, products and services comply with all relevant environmental regulations

Developing and communicating an environmental policy

Training and awareness
Creating procedures for controlling activities with significant
environmental impacts

Fig. 2. Environmental measures which should be incorporated into the Environmental Management System.

most construction and engineering projects. Processes around consultation with the local community into environmental issues and corporate social responsibility to maintain or enhance their well-being, environment and facilities can prove extremely fruitful in most cases. In addition, becoming accredited with schemes such as the Considerate Contractors Scheme in the UK can pay dividends and enhance the reputation of the project team.

Once again, the collaboration toolkit can play an important part on bringing parties together, formally or informally to present innovative ideas and solutions in this regard.

\subsubsection{Education around environmental sustainability}

Engineering and construction projects should "promote sustainability and social responsibility" through teaching, learning and research. The collaboration toolkit encourages industry partnerships and therein can encourage teaching and learning. As part of construction and engineering projects using the toolkit, strategies should be focused on the environmental sustainability of all operations and teaching, learning and research around this agenda through education programmes and continuous professional development should be encouraged. In this way construction and engineering projects could be regarded as a "Living Laboratories" especially when partnering with specialist energy partners.

\subsection{Successful outcomes that the collaboration toolkit has had on delivering environmental sustainability}

Although projects where the collaboration toolkit is being piloted, are at a relatively early stage in terms of delivery, they are proving to have many beneficial outcomes from an environmental sustainability perspective. For the client body these include those benefits shown in Figure 3.

\section{Conclusions}

The collaboration toolkit has been presented and as previously outlined forms part of action research as part of an ongoing case study where it is being piloted on UK construction projects. It has so far, since it was introduced in 2018 has achieved very successful outcomes for the client organisation in the UK and facilitated and encouraged many different environmental sustainability initiatives and policies to be brought forward. In this way it has assisted the organisation tokeep on target with its environmental sustainability objectives. It has created the collaboration and partnering ethos that is so important for innovation and delivery strategies linked to environmentally sustainable construction and engineering projects and processes that could otherwise have been problematic. 


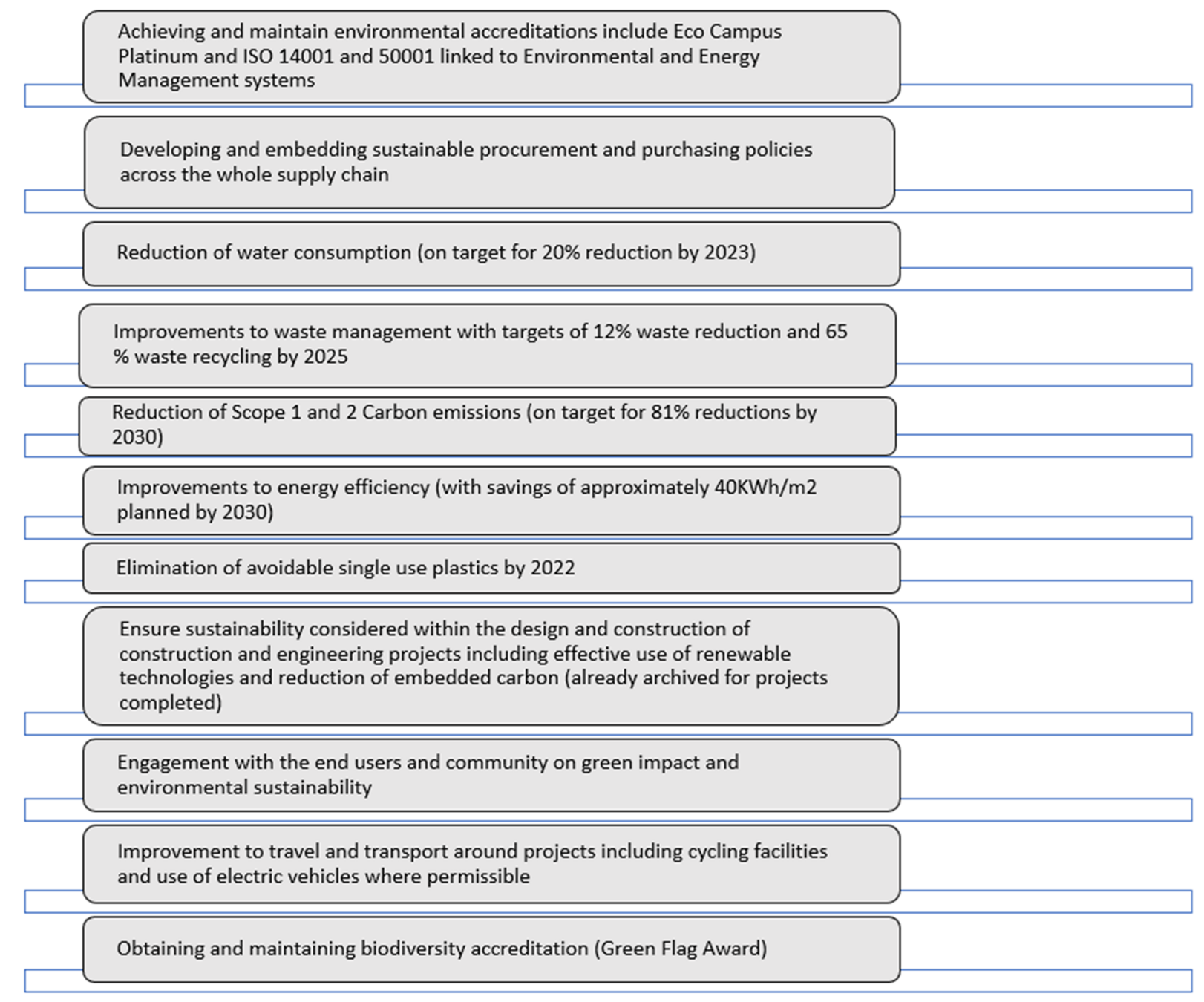

Fig. 3. Beneficial outcomes as part of the case study.

\section{Recommendations}

The benefits of utilising the toolkit have been clearly articulated in this paper. Accordingly, it is hoped that the toolkit can provide the right platform for construction and engineering projects in Ajman and therein achieve similar environmentally beneficial outcomes for the emirate. For this reason, it is recommended that the principles and mechanics of the toolkit be deployed when embarking on environmental projects as part of the emirate's aspirations for a more sustainable future

\section{References}

1. H. Patel, M. Pettitt, J.R. Wilson, Factors of collaborative working: a framework for a collaboration model, Appl. Ergon. 43, 1-26 (2012)

2. Construction Industry Council, A guide to project team partnering, 2016. hyyp://www.cic.org.uk (accessed December $6,2016)$
3. J. Egan, Rethinking construction. The report of the construction task force, London DETR. TSO. 18-20, 1998.

4. J. Egan, Accelerating change. Rethinking construction, Strategic Forum for Construction, London, 2002

5. M. Latham, Constructing the team, The Stationery Office, London, 1994

6. T.I. Vaaland, Improving project collaboration: start with the conflicts, Int. J. Proj. Manag. 22, 447-454 (2004)

7. P.T. Chow, S.O. Cheung, K.Y. Chan, Trust-building in construction contracting: mechanism and expectation, Int. J. Proj. Manag. 30, 927-937 (2012)

8. M.M. Kumaraswamy, J.D. Mathews, Improved subcontractor selection employing partnering practices, J. Manag. Eng. 16, 47-57 (2000)

9. M.M. Kumaraswamy, F.Y.L. Yean, M.M. Rahman, S.T. Phng, Constructing relationally integrated teams, J. Constr. Eng. Manag. 131, 1076-1084 (2005)

10. A. Ross, Supply chain management in an uncertain economic climate: a UK perspective, Constr. Innov. 11, 5-13 (2011)

11. A. Dainty, G. Briscoe, J. Millet, Subcontractor perspectives on supply chain alliances, Constr. Manag. Econ. 19, 841-848 (2001) 
12. K. Langfield-Smith, The relations between transactional characteristics, trust and risk in the start-up phase of a collaborative alliance, Manag. Account. Res. 19, 344-464 (2008)

13. S.C. Silva, F. Bradley, C.M.P. Sousa, Empirical test of the trust performance link in an international alliances' context, Int. Bus. Rev. 21, 293-306 (2012)

14. S. Rowlinson, F.Y.K. Cheung, A review of the concepts and definitions of the various forms of relational contracting, in: S.N. Kalindindi, K. Varghese (Eds.) Proceedings of the International Symposium of CIB W92 on Procurement Systems, 7-12 January 2004, Chennai, India, pp. 227-236

15. J.K. Pinto, D.P. Slevin, B. English, Trust in projects: an empirical assessment of owner/contractor relationships, Int. J. Proj. Manag. 27, 638-648 (2009)
16. J.A. Colquitt, B.A. Scott, J.A. LePine, Trust, trustworthiness, and trust propensity: a meta-analytic test of their unique relationships with risk taking and job performance, J. Appl. Psychol. 92, 909-927 (2007)

17. P.P. Li, Toward a geocentric framework of trust: an application to organisational trust, Manag. Organ. Rev. 4, 413-439 (2008)

18. R.M. Kramer, Trust and distrust in organisations: emerging perspectives enduring questions, Ann. Rev. Psychol. 50, 569-598 (1999)

19. M. Sheehan, D. Kearns, Using Kolb: implementation and evaluation of facilitation skills, Ind. Commer. Train. 28, 5-13 (1995)

Cite this article as: Jason Challender, Achieving sustainability and environmental enhancements through a "collaboration toolkit" to deliver new sustainability strategies for The Emirate of Ajman - UAE, Renew. Energy Environ. Sustain. 6, 16 (2021) 